\title{
Literature Circles with the Seventh-Grade Reluctant Second Language Readers
}

\author{
Min-Hsun Chiang \\ Department of Foreign Languages and Literature \\ Tunghai University \\ Taiwan
}

\begin{abstract}
This study explored the effects of literature circles on cultivating self-efficacy as $7^{\text {th }}$ grade L2 readers engaged in weekly reading activities. An intact class of $28,7^{\text {th }}$-grade students from a public junior high school in central Taiwan were recruited to take part in a 12-week, literature circle-integrated reading program. Pre-and post-test of their self-efficacy were calculated to identify any statistically significant difference before and after the reading program. Pearson correlation was calculated to identify any correlation between the participants' self-efficacy and reading comprehension. The results show that there is no significant difference in self-efficacy after participating in the program. However, a moderate correlation between self-efficacy and reading comprehension measure was identified. Most participants applauded the interactive and collaborative nature of the literaturecircle reading activities.
\end{abstract}

Keywords: English as foreign language, L2 reading, self-efficacy, literature circles, cooperative/collaborative learning, reading comprehension

\section{Introduction}

Reading is fundamental to the development of other skills in foreign language. Without solid reading skills, English language learners fall short of expanding their linguistic repertoire and handicap themselves of further developing their speaking and writing in English. Many English language learners recognize the importance of reading but lack impetus to sharpen their reading skills. This lack of momentum is particularly evident among Taiwanese junior high school students due to the test-oriented education system, which places less emphasis on cultivating purposeful reading in English. The typical English reading materials for junior high school students in Taiwan include textbooks, test-prep books, and assigned readers. Rarely will the students have opportunity to read English for pleasure. To them, most likely, reading in English equals preparing for the test and getting a good score. As a result, many junior high students in Taiwan don't like to read in English but rather spending their leisure time texting, messaging, Facebooking, and Instagramming. Recognizing the importance of reading and the low motivation among junior high students, many English teachers in Taiwan are constantly seeking alternative teaching approaches and classroom activities to kindle their students' reading interest. Inspired by the positive results from the implementation of literature circles (LCs) in the tertiary level (Chiang, 2007; Chiang, 2009), the researcher of the current study set out to explore the utilization of LCs with junior high students and investigate the potential effects of LCs on boosting the intended language learners' self-efficacy and the possible link between self-efficacy and reading comprehension gains.

\section{Review of Related Literature}

\subsection{Theoretical Underpinning of Literature Circles}

LCs are temporarily formed small groups of students within a class where the students choose their own reading materials, decide their own reading schedule, take on various group roles and meet on a regular basis to help each other develop deeper understanding of the commonly chosen reading texts (Daniels, 1994; 2002). From its inception in Chicago's public schools in the 1990s, the idea has been adopted, adapted, and carried out by many language arts teachers in the States. With phenomenally successful reports from the first language (L1) application, the same idea has been extended to the promotion of second/foreign language reading with promising outcomes in developing reading comprehension (Lin, 2006; Hsu, 2004), enhancing reading motivation (Burns,1998; Jewell \& Pratt,1999), cultivating learner autonomy, and promoting critical thinking skills (Chiang, 2009). 
The merits of LCs are hinged upon three complementary conceptual frameworks, including collaborative and cooperative learning, reader response theory, and learner-centered learning.

\subsubsection{Cooperative and Collaborative Learning}

The concept and procedures of LCs are based upon the cooperative and collaborative learning principles rooted in Vygotsky's (1978) "zone of proximal development" (ZPD). ZPD refers to "the distance between the child's actual developmental level as determined by independent problem solving and the level of potential development as determined through problem solving under adult guidance or in collaboration with more capable peers" (Vygotsky, 1978, p. 86). LCs provide learners with opportunities to solve problems by interacting with more capable peers who lead them to a higher level of understanding by stretching their ZPD. LCs are not only well informed by the cooperative principles but also manifest Johnson \& Johnson's (1999) five essential elements of cooperative learning groups. The five elements are (1) face-to-face interaction; (2) positive interdependence; (3) collaborative skills; (4) individual accountability; and (5) group processing. In short, LC lends itself seamlessly to the cooperative learning and is considered an ideal context in which the foreign language learners are able to learn interactively, cooperatively and effectively (Chiang, 2007).

\subsubsection{Reader Response Theory}

Literature circles are in line with the reader response principles. Rosenblatt (1995) views reading as a transaction between the reader and the text. She postulates that a text is lifeless until a reader comes to be in contact with the text and breathes in his/her interpretation of it. When reading a text, the readers approach the text from different perspectives, bring their prior knowledge, experiences, values and beliefs to the text and interact with the text. In the process of transaction, the readers construct meaning out of the text with their own interpretations. Rosenblatt (1995) further explains that different readers have different interpretations of a literary work and there is no correct one. Resonating with Rosenblatt's idea, Probset (1988) and Daniels (2002) maintain that any work of literature is a collaboration between a reader's prior experiences and the words of the author. That is, encouraging readers' responses to the reading text facilitate active and meaningful reading (Rosenblatt,1995).

\subsubsection{Learner Centeredness}

Learner centeredness is considered another prominent feature of LCs. Learner centeredness is related to learners' capacity in choosing what they like to do and learn in the classroom. In contrast to traditional teacher-centered instruction, in LCs, students choose their own reading materials, decide the amount of reading through peer negotiation, develop their own discussion topics, share their responses with peers, and sometimes learn to settle arguments or different interpretations. In other words, students are the center of decision-making process. According to Daniels (2002), student choice is the key ingredient of LCs. Unlike teacher-centered classroom where teachers control the reading assignments, in the student-centered activity like LCs, teachers serve as facilitators who guide and help students make their own choices and be in charge of their own behavior in an autonomy-supporting learning community. A number of researchers claim that allowing students opportunities to make choices of their reading and take some control over what they learn positively influence students' intrinsic motivation to read (Deci \& Ryan,1985; Gambrell,1996; Guthrie, Wigfield \& Perencevich, 2004).

\subsection{Empirical findings of implementing LCs}

Over the decades, LCs have been broadly adopted in both L1 and L2 contexts. Substantial research reveals that LCs have positive effects on encouraging learner responses (Gilbert, 2000; Kim, 2004), promoting reading comprehension (Chiang, 2007; Parker, Quigley \& Reilly, 1999; Tierney \&Readence, 2000), increasing motivation to read (Burns,1998;Jewell \& Pratt,1999; Loffredo, 2004), and cultivating self-efficacy (Kim, 2004; McElvain, 2010).Much of the research in the EFL context has focused on learners' reactions to the LC activity (Mark, 2007; Williams, 2011). One study reported some benefits of LCs through the participants' self-evaluation, including enhanced reading fluency, broadened vocabulary knowledge, and improved speaking skills (Shelton-Strong, 2012). In Furr's (2007) adaptation of LC activities for EFL college students in Japan, Furr proposed modifying Daniels' guidelines for EFL learners. He specifically suggests that teachers should select reading materials so as to better match students' reading levels and that post-reading circle discussions can involve some language teaching activities to clarify parts of the story or facilitate discussion in the L2. The review of prior research on LCs indicates that there are more studies focusing on the college and elementary level than the secondary one. Thus, more studies are needed to shed light on how LCs can be incorporated into the L2 reading at the junior high schools where many L2 readers are struggling with low motivation and confidence in tackling English texts. 


\subsection{Self-Efficacy and L2 Reading}

Bandura (1977) stipulated self-efficacy as learners' faith about their ability to learn particular tasks or skills. Learners with high self-efficacy tend to face challenge rather than avoiding it and are able to recover quickly from setback. They are willing to invest more effort and are predicted to perform well in specific tasks. In contrast, learners with low self-efficacy suspect their ability and incline to avoid tough tasks; they rather choose less challenging tasks and give up easily. Therefore, Bandura proposed that "the stronger the perceived self-efficacy, the higher the goal challenges people set for themselves". Learners' belief about their own capability will determine whether they will face or avoid the challenge. Motivation also plays a role in learners' efficacy. Students with firm belief of efficacy are more likely to motivate themselves to tackle challenge. They usually set goals for themselves and are determined to reach their destination. Bandura (1977) listed four crucial sources of self-efficacy, namely mastery experiences, vicarious experience, social persuasion, and emotional state. Research in this area has validated the important implications of self-efficacy theory in academic settings where learners' self-perceived efficacy has a direct and/or indirect effect on academic achievement (Caprara et al., 2008).

In EFL setting, the empirical studies on self-efficacy and L2 reading revealed that self-efficacy is positively correlated with reading comprehension, reading intervention, and strategy use (Ghonsooly \& Elahi, 2010; LeBlanc, 2015). However, self-efficacy is negatively correlated with language anxiety. For example, LeBlanc's (2015) quasi-experimental study with 316 Japanese high school students shows that after taking part in LCs over the course of one academic year, the subjects' reading self-efficacy was improved significantly while reading anxiety significantly decreased. Similarly, Ghonsooly and Elahi (2010) identified the correlation between EFL students' self-efficacy and their reading anxiety and comprehension. The authors administered two questionnaires on readers' anxiety and self-efficacy to 150 Persian-speaking sophomores at three universities in Iran and compared the efficacy scores with students' scores of their final reading exam. Ghonsooly and Elahi found that students with higher self-efficacy performed better in their reading scores, and their anxiety was lower than students with low self-efficacy. The authors also suggest that the teachers should cultivate students' awareness of self-efficacy and design classroom activities that help enhance self-efficacy and lower language learning anxiety. However, in foreign language learning, how to promote students' self-efficacy as L2 reader via meaningful reading activities remains puzzling. Therefore, this case study intended to explore whether students' efficacy would increase during a 12-week literature circle classes, and also examine whether learners' reading comprehension is related to their self-efficacy. The following three research questions guided the data collection and analysis of the current study:

1) Is there any significant difference in the students' read-related self-efficacy before and after taking part in a 12-week, LC-integrated reading class?

2) Is there any correlation between the students' self-efficacy and their reading comprehension gains?

3) What are the students' perceptions of their English reading self-efficacy and their participation in LCs?

\section{Method}

A mixed method approach was adopted with 28 junior high school students to gather both quantitative and qualitative data. An intact $7^{\text {th }}$ grade class of 10 males and 18 females from a public school in central Taiwan were recruited to take part in a 12-week, LC-integrated reading program. The class met once a week for an hour. The students were first introduced to the concept of LCs and then guided to become familiarized with four LC roles, including connector, question writer, vocabulary finder, and story mapper. Rosenblatt's reader response theory is manifested in the LC discussions as the students approach the text from various discussion roles, such as the Connector who connects the individual reader's experiences with the text, the Question writer who raises questions about the content of the text, and the story mapper who offers graphic representation of the test. Seven mixed-proficiency circles were formed based on their English teacher's suggestion. Instead of letting students choose their own reading materials, the Oxford level 4 reader 'In the Caves' was selected based on the students' current reading level. This decision was made in reference to Furr's (2007) suggestion that in the EFL context, the teachers have better knowledge in selecting proper English readers for their pupils. Data were collected and analyzed quantitatively and qualitatively from a self-efficacy questionnaire, reading comprehension worksheets, and an open-ended survey. A self-efficacy questionnaire (see Appendix A) with 20 items rated on 4-point Likert scale was administered to the students before and after the 12-week, LC-integrated reading program. The satisfactory reliability coefficient of the questionnaire was obtained at .93 . A paired-samples t-test was run on SPSS 23 to detect any significant difference between the pre- and post-score of self-efficacy. 
To investigate if there is any relationship between self-efficacy and reading comprehension, an average of every students' five reading comprehension worksheets and each student's self-efficacy postscore were entered to run Pearson correlation. In addition to the statistical analyses, an open-ended survey regarding L2 reading motivation/confidence, LC activities, and L2 reading in general was distributed to the students at the end of the $12^{\text {th }}$ week. To tap into the students' perspectives of LC intervention, their responses were coded and categorized to inform future application of LC in EFL contexts.

\section{Results and Discussion}

4.1 There is no significant difference in the students' reading-related self-efficacy before and after the 12week, LC-integrated reading program.

The pair-samples t-test of the subjects' pre and post score from the self-efficacy questionnaire indicates that the subjects' self-efficacy doesn't reach statistical significance. In other words, taking part in LC discussions didn't significantly increase the subjects' self-efficacy as L2 readers. As Table 1 shows, the mean score of 28 students' self-efficacy climbed from 2.63 to 2.73 at the end of 12-week LC-integrated reading program.

Table 1. Paired Samples Descriptive Statistics of Self Efficacy

\begin{tabular}{lllll}
\hline & Mean & $\mathrm{N}$ & Std. Deviation & Std. Error Mean \\
\hline Pretest & 2.63 & 28 & .49 & .092 \\
\hline Posttest & 2.73 & 28 & .55 & .10 \\
\hline
\end{tabular}

\begin{tabular}{|c|c|c|c|c|c|c|c|c|}
\hline \multirow[t]{3}{*}{ Test pairs $=28$} & \multicolumn{5}{|c|}{ Paired Differences } & \multirow[t]{3}{*}{$\mathrm{t}$} & \multirow[t]{3}{*}{$\mathrm{df}$} & \multirow[t]{3}{*}{ Sig. (2-tailed) } \\
\hline & \multirow[t]{2}{*}{ Mean } & \multirow[t]{2}{*}{$\begin{array}{l}\text { Std. } \\
\text { Deviation }\end{array}$} & \multirow[t]{2}{*}{$\begin{array}{ll}\text { Std. } & \text { Error } \\
\text { Mean } & \end{array}$} & \multicolumn{2}{|c|}{$\begin{array}{l}95 \% \text { Confidence Interval } \\
\text { of the Difference }\end{array}$} & & & \\
\hline & & & & Lower & Upper & & & \\
\hline $\begin{array}{l}\text { Pretest } \\
\text { Posttest }\end{array}$ & -.100 & .36 & .068 & -.24 & .039 & -1.477 & 27 & .151 \\
\hline
\end{tabular}

However, Table 2 indicates that there is no significant difference in the students' pre and post self-efficacy scores. Even though there is no significant difference in the paired-samples t-test, it's worthwhile to scrutinize the various items comprising the questionnaire. Chart 1 compares the pre and post mean scores for 20 items. Out of 20 items, seventeen of them have higher mean post scores whereas three of them have lower ones. These three items are item 2, 9, and 19. Both item 2 and 19 are pertaining to the students' confidence and interest in reading English while item 9 probes into students' perceived competence of being a vocabulary finder, the easiest LC role among the four roles chosen for this class. The decreased mean postscore from item 2 suggests that the 12-week, LCintegrated reading activities didn't boost up students' self-efficacy as L2 readers. This finding contradicts the substantially increased postscore from item 13 stating "I believe that if I try hard, I can solve the problems by myself while reading and writing in English". The contradiction between item 2 and 13 may suggest that the students might not feel more confident about their L2 reading in general; nevertheless, with their success experience from the LC activities, the students came to see their potentiality as effective readers in English. Item 12 receives the greatest increase in the postscore (from 2.18 to 2.57), which probes into the students' confidence of taking on story mapper role in LCs. It suggests that the majority of the students consider themselves improve the most in graphically expressing their understanding of the reading text. Similarly, the students also see themselves improve substantially as a question writer as they rated themselves higher in the posttest for item 11. Ironically, the one single item (19) that dropped the most from pre to post score is tapping into the students' interest in reading English. This finding is inconsistent from the results gathered from the open-ended survey, which will be presented and discussed in the later section. 


\section{Chart1. Pretest and posttest of Self-Efficacy: Item by item comparison}

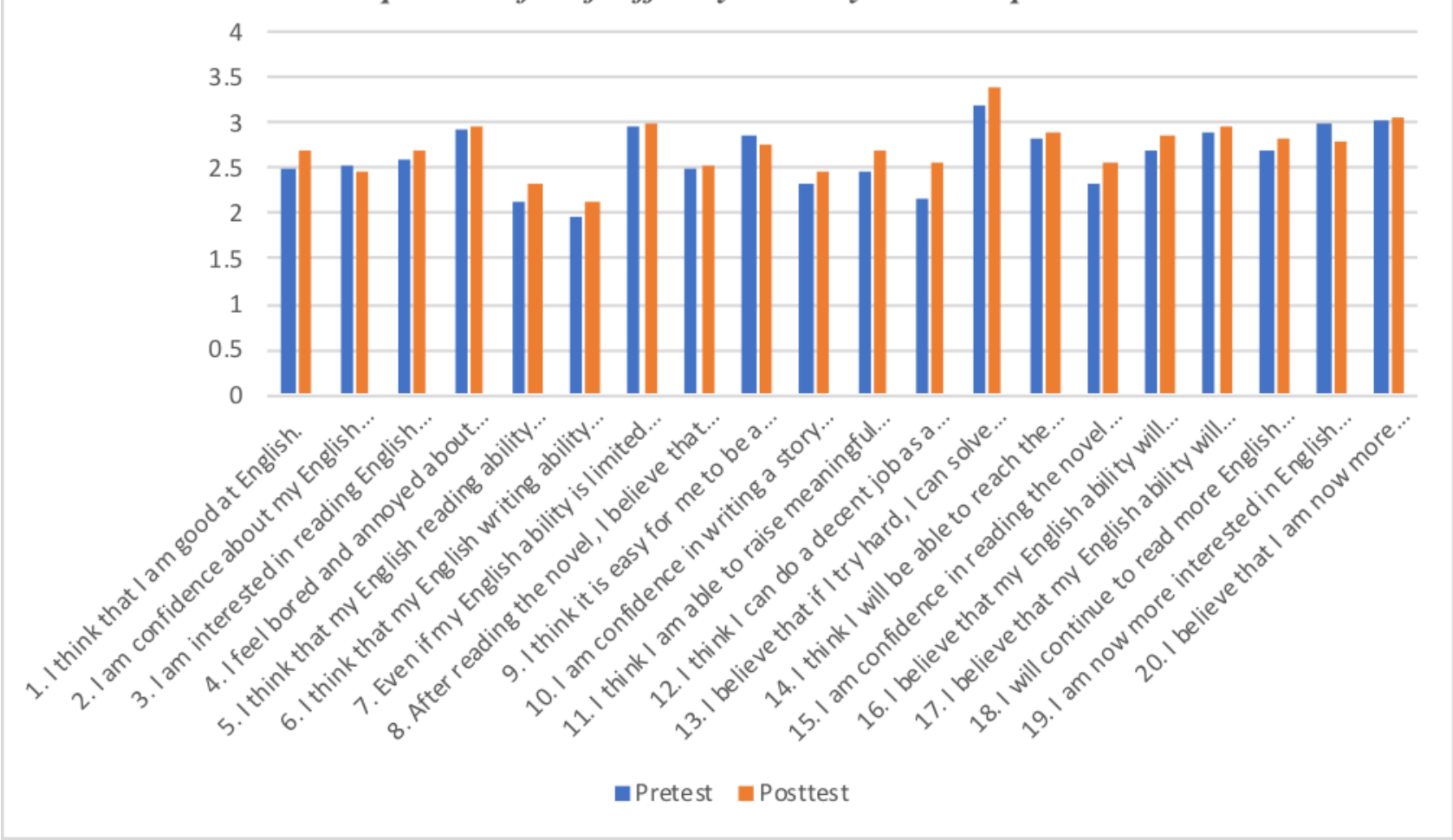

Unlike the prior research concluded with increased self-efficacy and enhanced intrinsic motivation to L2 reading as a result of LC intervention (Burns,1998; Jewell \& Pratt,1999; Loffredo, 2004; Kim, 2004; McElvain, 2010), the current study shows that LCs didn't considerably cultivate the students' self-efficacy, an integral construct of motivation to read. The insignificant difference may be attributed to the limited learner choice in selecting reading materials in the current study. That is, without giving students a full capacity to decide on the reader for their LC meetings, the students didn't develop a sense of ownership in their reading engagement, which might have compromised the learner-centeredness nature of LCs. This speculation resonates with Deci \& Ryan's (1985) cautionary remark stating that teachers who do not support student choice of their own reading materials and fail to see students as independent learners will undermine their students' reading motivation. Nevertheless, providing students with too many choices to manage may also result in loss of motivation. Teachers should offer an appropriate range of choices of reading materials for students, accompanied by instruction and guidance (Guthrie, Wigfield \& Perencevich, 2004).

\subsection{A moderate correlation was identified between the students' elf-efficacy and reading comprehension gains.}

The scatterplot (Graph 1) suggests a definite relationship between reading comprehension and efficacy, with larger values of reading comprehension tending to be associated with larger values of efficacy. There appears to be a positive correlation between the two variables. A Pearson's correlation was run to determine the relationship between 28 seventh-graders' self-efficacy and reading comprehension gains. Table 3 shows that there is a moderate, positive correlation between self-efficacy and reading comprehension gains $(\mathrm{r}=.479, \mathrm{~N}=14, \mathrm{p}<.01)$. Averages of the scores form all the subjects' reading comprehension worksheets and their postscores from the self-efficacy questionnaire were entered to run Pearson correlation. A moderate correlation between the students' self-efficacy and reading comprehension worksheet average suggests that a positive correlation exists between the two. However, it remains unclear as to whether self-efficacy facilitates the development of better reading comprehension or the other way around. That is, the students' reading comprehension improvement boosts up their self-efficacy. A statistically significant correlation shows that self-efficacy and reading comprehension are positively related to each other. When self-efficacy rises, reading comprehension goes up, and vice versa. This finding is consistent with the prior research in which a positive correlation between self-efficacy and reading comprehension was found (Ghonsooly \& Elahi, 2010). 


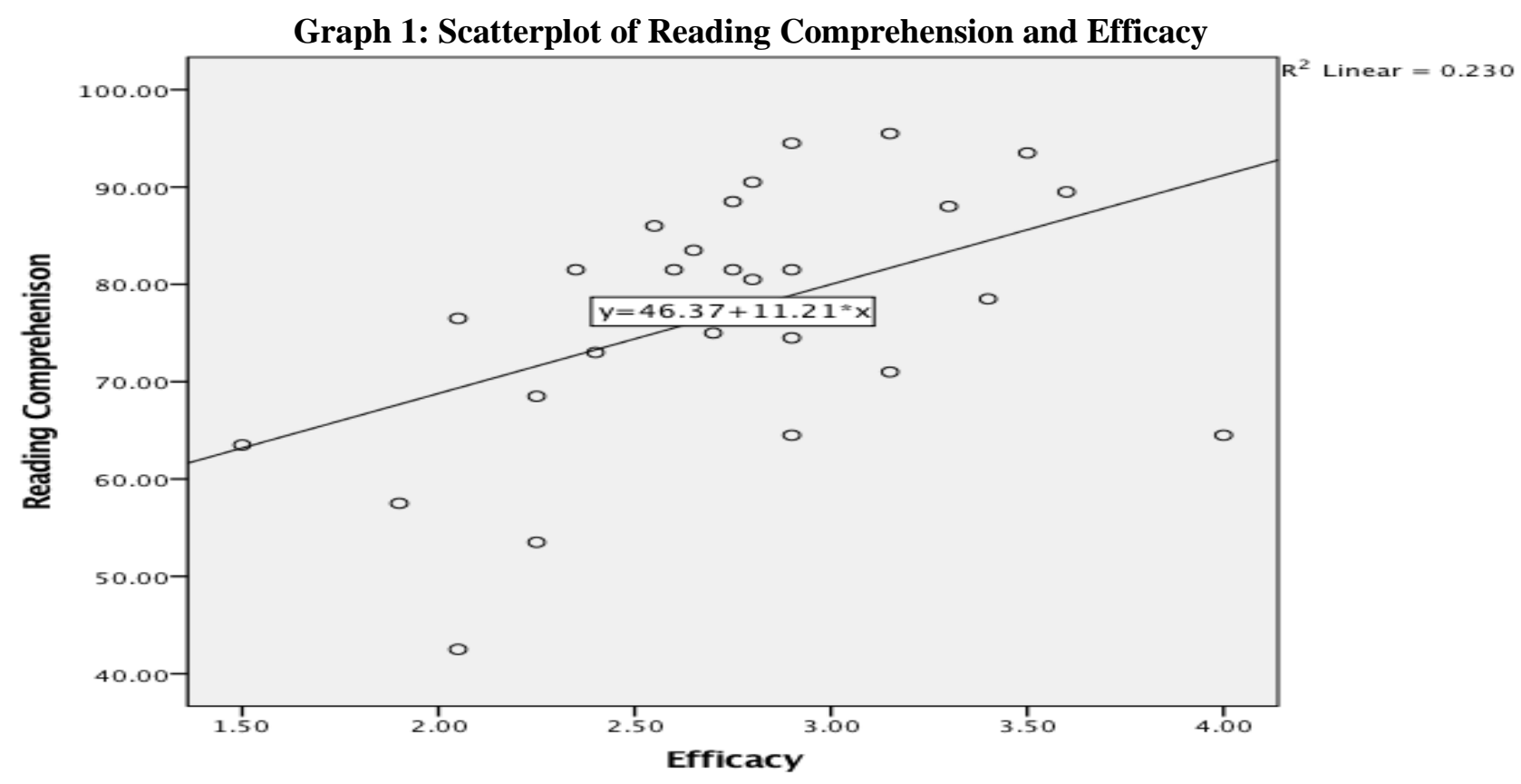

Table 3. Pearson Correlations of RC \& Efficacy

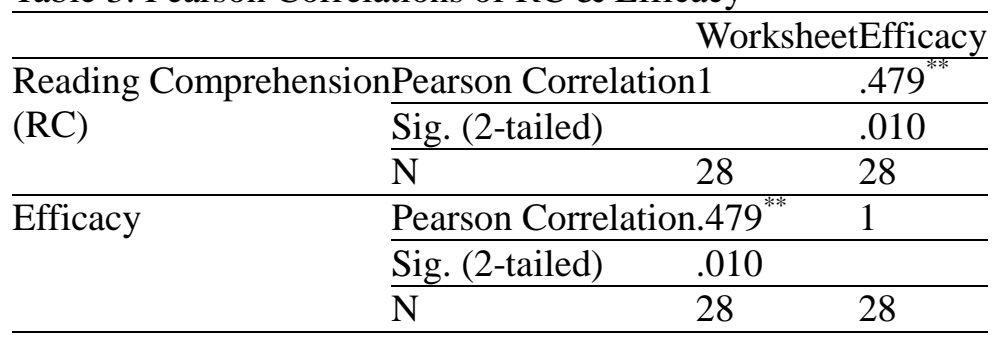

**Correlation is significant at the 0.01 level (2-tailed).

4.2 The majority of the students considered LCs an interesting and effective reading activity and acknowledged the fact that they became more confident about reading English novel as a result of taking part in LCs for 12 weeks.

Based on the content analysis of the students' written responses to the open-ended survey, most students recognized two positive outcomes of LCs, namely improved reading comprehension and enhanced motivation and confidence in reading English.

The students also articulated some concerns and barriers they encountered while partaking in LCs. As for the benefits, twenty-four out of 28 students mentioned their reading comprehension has been improved as a result of 12-week LC reading. The majority of the participants (82\%) considered LCs helpful in advancing their reading efficiency and improving their overall English proficiency. Most importantly, ninety percent of the participating students said that their English reading comprehension ability has been improved via LCs. One student wrote in the survey,

"I think Literature Circles have improved my reading comprehension ability significantly. During each session, I have the chances to play different roles and practice different reading strategies. If I have problems, I discussed them with my group members and they are willing to help. Now I am not afraid of reading English stories anymore. I can easily get the main idea of an article and I read faster and more effectively than before. Reading and discussion with peers is much more fun and less stressful to me now."

Another student mentioned that LCs also helped improve his English reading comprehension performance,

"In Literature Circles, I realized that each role is just like a reading strategy. By rotating each role in each session, I found myself analyzing the text easily and effectively. Meanwhile, discussing the story with my group members also enhanced my understanding of the story because I think sharing my opinions and discussing it with others can solve my misunderstandings of some parts of the story and received different opinions from others. 
For me, Literature Circles was fun and cool because they not only improve my English reading comprehension ability but also increases my reading speed. I really enjoyed reading in Literature Circles."

The results indicate that the students enjoyed reading in LCs and believed their reading comprehension ability has been enhanced. Apart from the improvement in reading comprehension, the students also attributed the improvement to the collaboration taking place in their LCs. Vygotsky's notion (1978) of learning through social interaction and collaborative learning has been fully manifested as the members of the same circle worked together and helped one another to understand the reading texts and thus facilitated reading comprehension. This finding appears to be consistent with previous studies (Chiang, 2007; Hsu, 2004; Lin, 2006; Parker, Quigley \& Reilly, 1999; Tierney \& Readence, 2000) that LCs can exert positive influence in promoting reading comprehension through collaborative learning. Second, many students acknowledged that they have become more confident and motivated to read English. One student, Eason, mentioned that his confidence in English reading has been boosted via LCs, where he developed a sense of achievement as he overcame some initial obstacles in leading the circle discussion.

"I think Literature Circles not only enhanced my motivation for English reading but also built up my confidence in learning English. That is to say, at first, I was asked to be the group leader and help my group members. However, I am a shy person who did not talk a lot in class. At the first few sessions, our group did not work smoothly since most of us did not actively join the discussion. However, I noticed that one of our group members, Jane, was not interested in reading English stories and seemed gloomy during the whole class. After talking to her, I realized that she did not know how to continue the designated task., I decided to help her by explaining and discussing the story with her. Subsequently, I noticed that Jane has become much more interested in reading English story. She started to take part in the discussion and read the story actively. Moreover, I started to encourage other group members to help each other because I knew teamwork is very important in Literature Circles. We are a totally different group now and I love our group. Most importantly, I felt the sense of achievement by serving as a group leader and guiding the whole group to read successfully."

This statement contradicts the insignificant difference derived from the paired-samples t-test of self-efficacy questionnaire. Eason is not the only one mentioning his enhanced self-efficacy in reading. This inconsistence may be due to the fact that some students, like Eason, did experience success in reading English texts and developed sense of confidence whereas some didn't. That's why the overall difference didn't reach statistical significance. Many participants admitted that they were not interested in English reading in the first place because they don't have confidence, especially when they have to cope with unknown English texts themselves without any guidance or support. Nevertheless, when they are in the LCs consisted of students with various English proficiency, they can seek help from their group members to comprehend the texts (Johnson \& Johnson, 1999). LCs give students ample opportunities to accumulate successful reading experiences, which in turn helps develop students' selfefficacy in reading (Bandura, 1977).

In addition, observing their peers perform reading activity in LCs also helped promote the students' confidence in handling their reading anxiety; consequently, they became more willing to take risks and persist in completing a reading task even when the reading texts appear to be relatively difficult or challenging (Schunk, 2003). The enhancement in the students' self-efficacy will ultimately motivate them to read more. Furthermore, the students also brought up their retrospective distresses as the program ended. They were mainly concerned with their varied familiarity with different circle roles and the distracting off-task behaviors. Some students recalled when they were not familiar with certain LC responsibilities, they tended to consider the task difficult and became less confident. The students also reminisced about the disruptive off-task conversations taking place while the LC discussions were in progress. Many of the students didn't know how to redirect the discussion towards the intended goal since they were not used to collaborating with one another in a small group setting.

\section{Pedagogical implications and conclusion}

Despite the inconsistent findings from the quantitative and qualitative measure of self-efficacy before and after the 12-week, LC-integrated reading program, several advisable pedagogical implications emerged from the current study. First, LCs can be an effective and motivating reading activity for L2 readers. The majority of the students applauded the interactive nature and collaboration opportunity provided by LCs. They also believed that participating in LCs has helped them read with greater comprehension and boost their reading self-efficacy. 
Given the test-oriented English learning environment, it is difficult to motivate EFL junior high schoolers to spontaneously read English materials outside of the classroom. LCs offers a supportive, trusting, and collaborative reading context in which L2 readers can experience success in English reading and subsequently boost their motivation. It might be worthwhile to integrate LCs with other instructional methods, such as guided reading, whole class discussion, or reader theater to explore the potentialities of various strategies. Second, it's still a dilemma for EFL teachers to make decision as to whether their L2 students should choose their reading materials for LC discussion. The current finding suggests that without giving the students the opportunity to choose their reader, the full potential of cultivating self-efficacy via LCs may be truncated. Based on the advice by the prior LC researchers in the EFL context, it may be more beneficial for teachers to choose suitable readers for their students. To take both sides into consideration, providing EFL readers with a short list of readers to choose from may constitute an optimal solution to bring out the full potential of LCs as an efficacious pedagogy. Third, cultivating L2 students' awareness of self-efficacy via LCs will go a long way as they continue to develop their language proficiency. In light of the positive correlation between self-efficacy and reading comprehension, LCs appear to create a suitable milieu in which EFL readers can experience success as they connect what they have read with their lives and encourage one another when stumbling over difficult texts. Once the students have developed stable self-efficacy as EFL readers, they will be able to keep pressing on as they tackle next reading challenge. Finally, concrete modeling, multiple practices of various circle roles, and constant monitoring are very key to the successful implementation of LCs in EFL context. Several students voiced their lack of ability to be in charge of the LC discussion, especially when the discussions were constantly interrupted by off-task conversations. Therefore, one important caution when implementing LCs is the full and concrete modeling of the discussion roles, so that the students will read the texts with a specific purpose and be confident about what to anticipate as the group discussion unfolds. In addition, although the teacher being a facilitator is one of the features of LCs, it is suggested that the teacher might need to monitor group discussions and intervene with discretion to model appropriate turn-taking skills and encourage productive discussions when the conversations appear to be at the verge of chaos.

To conclude, LCs can be an efficacious reading method for L2 readers given concrete modeling and adequate teacher monitoring as well as some freedom to choose from a list of suggested English readers. Through LC discussions, the students have ample opportunities to read English texts and express their thoughts and feelings in a peer-supportive environment. It is believed that such interactive and collaborative reading mode would enhance language learners' reading comprehension performance. For future research, it will be worthwhile to implement LCs for a longer period of time with experimental and control group design and investigate the individual reading comprehension gains between the two groups, which will bring to light the effects of LCs on reading comprehension.

\section{References}

Bandura, A. (1977). Self-efficacy: Toward a unifying theory of behavioral change. Psychological Review, 84, 191-215.

Burns, B. (1998). Changing the classroom climate with literature circles. Journal of Adolescent \& Adult Literacy, $42,124-128$.

Caprara, G. V., Fida, R., Vecchione, M., Del Bove, G., Vecchio, G. M., Barbaranelli C., \& Bandura, A. (2008). Longitudinal analysis of the role of perceived self-efficacy for self-regulated learning in academic continuance and achievement. Journal of Educational Psychology, 100(3), 525-534. doi:10.1037/00220663.100.3.525

Chiang, M. H. (2007). A novel idea: English as a foreign language reading via virtual literature circles. English Teaching and Learning, 31(4), 1-37.

Chiang, M. H. (2009). Cultivating critical thinking through literature circles in EFL context. Spectrum: Studies in Language, Literature, Translation, and Interpretation, 5, 89-116.

Daniel, H. (1994). Literature Circles: Voice and choice in the students-centered classroom. Portland, Maine: Stenhouse.

Daniel, H. (2002). Literature Circles: Voice and choice in book clubs and reading groups. Portland, Maine: Stenhouse. 
Deci, E. L., \& Ryan,R. M. (2000). Intrinsic and extrinsic motivation: Classis definitions and new directions. Contemporary Educational Psychology, 25, 54-67.

Furr, M. (2007). Reading circles: Moving great stories from the periphery of the language classroom to its centre. The Language Teacher, 31(7), 15-18.

Gambrell, L. B. (1996). Creating classroom cultures that foster reading motivation. Reading Teacher, 50(1), 1425.

Gilbert, L. (2000). Getting started: Using literature circles in the classroom. Primary Voices K-6, 9(1), 9-16.

Ghonsooly, B. \& Elahi, M. (2010). Learners' self-efficacy in reading and its relation to foreign language anxiety and reading achievement. Journal of English Language Teaching and Learning, 53(217), 45-67.

Guthrie, J. T., Wigfield, A. \&Perencevich, K. C. (2004). Scaffolding for motivation and engagement in reading. In J. T. Guthrie, A. Wigfield, \& K. C. Perencevich (Eds.), Motivating reading comprehension: Concept Oriented Reading Instruction (pp. 55-86). Mahwah, NJ: Erlbaum.

Hsu, J. Y. (2004). Reading without teachers: Literature circles in an EFL classroom.

The Proceedings of 2004 Cross-strait Conference on English Education, 401-421, Taiwan ELT Publishing Co., LTD.

Jewell, T., \& Pratt, D. (1999). Literature discussions in the primary grades: Children's thoughtful discourse about books and what teachers can do to make it happen. Reading Teacher, 52, 542-850.

Johnson, D. W., \& Johnson, R. (1999). Learning together and alone: Cooperative, competitive, and individualistic learning (5th ed.). Boston: Allyn \& Bacon.

Kim, M. (2004). Literature discussions in adult L2 learning. Language and Education, 18(2), 145-166.

LeBlanc, C. (2015). Investigating High School Students' Self- Efficacy in Reading Circles. The Language Teacher, 39(1), 15-21.

Lin, S. J. (2006). The effects of literature circles on EFL learning of children in a

bilingual class. Unpublished master's thesis, Kaohsiung Normal University. Kaohsiung, Taiwan.

Lofrredo, J. (2004). My first-hand experience with literature circles: A preservice teacher's reflections. The Ohio Reading Teacher, 36(2), 60-65.

Mark, P. L. (2007). Building community of EFL readers: Setting up literature circles in a Japanese university. In: K. Bradford-Watts (Ed.), JALT 2006 Conference Proceedings. Tokyo, Japan: JALT.

McElvain, C. M. (2010). Transactional literature circles and the reading comprehension of English learners in the mainstream classroom. Journal of Research in Reading, 33(2), 178-205. doi: 10.1111/j.14679817.2009.01403.X

Parker, S., Quigley, C., \& Reilly, J. B. (1999). Improving student reading comprehension through the use of literacy circles. Unpublished master's thesis, Saint Xavier University \& Skylight Publishing and Training, Chicago, Illinois. (ERIC Document Reproduction Service No. ED 433504)

Probset, R. (1988). Response and analysis: Teaching literature in the junior and senior high school. Portsmouth, NH: Heinemann.

Rosenblatt, L. (1995). Literature as exploration (Fifth edition). New York, NY: MLA of America.

Shelton-Strong, S. J. (2012). Literature circles in ELT. ELT Journal, 66(2), 213-223. doi:10.1093/elt/ccr049

Schunk, D. H. (2003). Self-efficacy for reading and writing: Influence of modeling, goal setting, and selfevaluation. Reading \& Writing Quarterly, 19, 159-172.

Tierney, R., \&Readence, J. (2000). Reading strategies and practices: A compendium. Boston, Massachusetts: Allyn and Bacon.

Vygotsky, L. S. (1978). Mind in society: The development of higher psychological processes. Cambridge, MA: Harvard University Press.

Williams, D. (2011). Student Reactions to literature circles in content-based instruction. In M. Pinto \& D. Shaffer (Eds.), Proceedings of PAC 2010, (pp. 219-231). Seoul, Korea: KOTESOL. 
Appendix A: EFL Reader's Self-Efficacy Questionnaire (Please rate the following 20 items from extremely true of me -4 , true of me- 3 , not true of me -2 to definitely not true of me-1)

\begin{tabular}{|c|c|c|c|c|}
\hline \multirow{2}{*}{$\begin{array}{l}\text { Item Statements } \\
1 . \text { I think that I am good at English. }\end{array}$} & 4 & 3 & 2 & \\
\hline & & & & \\
\hline \multicolumn{5}{|l|}{ 2. I am confidence about my English reading skills. } \\
\hline \multicolumn{5}{|l|}{ 3. I am interested in reading English books/novels. } \\
\hline \multicolumn{5}{|l|}{ 4. I feel bored and annoyed about English reading. } \\
\hline \multicolumn{5}{|l|}{ 5. I think that my English reading ability is better than anyone else in the class. } \\
\hline \multicolumn{5}{|l|}{ 6. I think that my English writing ability is better than anyone else in the class. } \\
\hline \multicolumn{5}{|l|}{$\begin{array}{l}\text { 7. Even if my English ability is limited now, I believe that I can try my best to read and } \\
\text { understand English novels. }\end{array}$} \\
\hline \multicolumn{5}{|l|}{ 8. After reading the novel, I believe that I know how to practice the four roles precisely. } \\
\hline \multicolumn{5}{|l|}{ 9. I think it is easy for me to be a vocabulary finder. } \\
\hline \multicolumn{5}{|l|}{ 10. I am confidence in writing a story summary. } \\
\hline \multicolumn{5}{|l|}{ 11. I think I am able to raise meaningful questions as a question writer. } \\
\hline \multicolumn{5}{|l|}{ 12. I think I can do a decent job as a story mapper. } \\
\hline \multicolumn{5}{|l|}{$\begin{array}{l}\text { 13. I believe that if I try hard, I can solve the problems by myself while reading and writing } \\
\text { in English. }\end{array}$} \\
\hline \multicolumn{5}{|l|}{ 14. I think I will be able to reach the reading goals of this literature circle program. } \\
\hline \multicolumn{5}{|l|}{ 15. I am confidence in reading the novel and practicing the four roles. } \\
\hline \multicolumn{5}{|l|}{ 16. I believe that my English ability will improve after reading the novel, In the Caves. } \\
\hline \multicolumn{5}{|l|}{$\begin{array}{l}\text { 17. I believe that my English ability will improve after practicing four roles in literature } \\
\text { circles. }\end{array}$} \\
\hline \multicolumn{5}{|l|}{ 18. I will continue to read more English texts/passages in order to strengthen my English. } \\
\hline \multicolumn{5}{|l|}{ 19. I am now more interested in English reading. } \\
\hline 20. I believe that I am now more confident abou & & & & \\
\hline
\end{tabular}

